
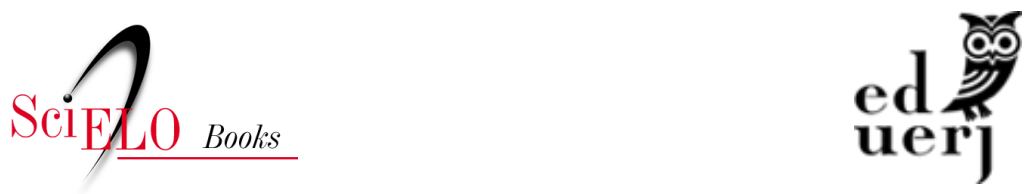

\title{
Apresentação Entrando na roda
}

\author{
Andrea da Paixão Fernandes \\ Paula Cid Lopes
}

\section{SciELO Books / SciELO Livros / SciELO Libros}

FERNANDES, A.P., and LOPES, P.C. Apresentação - Entrando na roda. In: FERNANDES, A.P., and LOPES, P.C., eds. O cotidiano escolar de crianças, jovens e adultos em rodas de conversas [online]. Rio de Janeiro: EDUERJ, 2020, pp. 13-19. ISBN: 978-65-87949-02-4. https://doi.org/10.7476/9786587949024.0001

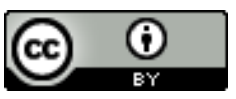

All the contents of this work, except where otherwise noted, is licensed under a Creative Commons Attribution 4.0 International license.

Todo o conteúdo deste trabalho, exceto quando houver ressalva, é publicado sob a licença Creative Commons Atribição 4.0.

Todo el contenido de esta obra, excepto donde se indique lo contrario, está bajo licencia de la licencia Creative Commons Reconocimento 4.0. 


\section{Apresentaçáo \\ Entrando na roda}

\section{A ação de extensáo universitária}

Este livro nasce da importância de revelarmos, para além dos muros de um projeto de extensão universitária de uma Universidade Pública, ${ }^{1}$ o conhecimento produzido com e pela ação extensionista. O projeto de extensão que ancora essa produçãa é o "Roda de Conversas - Cotidiano e Escola", tendo como objetivo geral promover discussóes sobre temáticas afins às questôes do cotidiano escolar, em sua diversidade e multiplicidade, e como objetivo específico viabilizar encontros temáticos, por diferentes campos de saberes ou áreas de formação, com vistas à promoção da reflexão sobre os temas abordados. Esse projeto nasce em 2015, tendo como foco os processos formativos no âmbito da educação. A primeira atividade desenvolvida, antes mesmo do cadastro do projeto de extensão junto ao Departamento de Extensão da UERJ, foi o evento Agentes Educadores em Roda de Conversas, em 2013, voltado para a formação de agentes educadores recém-chegados ao Instituto de Aplicaçáo Fernando Rodrigues da Silveira, o CAp-UERJ, e, recuperando outras açôes extensionistas desenvolvidas nas décadas de 1990 e 2000, o CAp Comunidade e o CAp-Social: articulaçóes e redes no Rio Comprido, respectivamente. Era o piloto do que

1 A universidade pública onde a mencionada ação extensionista se desenvolve é a Universidade do Estado do Rio de Janeiro (UERJ). 
seria, dois anos mais tarde, o projeto de extensão universitária de que tratamos aqui.

E é a partir daí que outras açóes em formato de roda de conversas se desenvolvem, tais como açóes do Projeto de Extensão Universitária "Roda de Conversas - Cotidiano e Escola", originado no Instituto de Aplicação Fernando Rodrigues da Silveira e em parceria com a Faculdade de Educação (EDU-UERJ) e que, posteriormente, em um movimento de construção de redes, amplia a parceria para o Instituto de Letras (ILE). Suas atividades se apresentam como possibilidades de formaçáo continuada de professores e de ampliação acadêmica para licenciandos em formação por meio de diálogo e debate sobre temas atuais da educação e da escola pública brasileira.

A concepção de rodas pressupóe o diálogo e a troca de conhecimentos e saberes entre os participantes de cada roda temática. Esse processo, que compreende movimentos de ensinaraprenderensinar, ${ }^{2}$ ocorre a partir de ideias e conhecimentos compartilhados e da valorização do saber do outro como aquele que pode complementar e ser complementado nas interfaces e interações possíveis em uma roda. É nessa perspectiva que o projeto se fundamenta teoricamente em Paulo Freire e nos círculos de cultura para o desenvolvimento de rodas de conversas temáticas, tendo como um dos objetivos assegurar aos seus participantes e proponentes espaçostempos de reflexão, articulando teoria e prática sobre os temas propostos para cada ciclo de debates. O projeto, que também pretende contribuir para a formação de professores autores, pesquisadores e reflexivos, ancora um conjunto de eventos para a circulação das discussóes de forma dinâmica e diversificada, se considerarmos as especificidades de cada temática da roda de conversas.

2 O movimento de ensinaraprenderensinar, ao ser grafado junto, como uma só palavra, indica uma indissociabilidade entre esses atos, além de serem um processo constante, que se realiza ao longo da vida. 


\section{O fortalecimento no contexto da crise do estado do Rio de Janeiro}

Os anos de crise no estado do Rio de Janeiro anunciados em 2015 e os difíceis momentos institucionais vividos como professoras de universidade pública e, em especial, da Universidade do Estado do Rio de Janeiro somavam-se à percepção de que a roda náo podia parar. Apesar de inevitavelmente afetada por todas as dificuldades que uma crise econômica e política promove, a UERJ, universidade pública, negava-se a sucumbir, e nossa luta por uma educação para todos e pelos diferentes e plurais caminhos de formaçáo era essencial nos percursos em que nos colocamos contra o desmonte de nossa Universidade. Todos os dias, enfrentávamos "leôes" em diferentes roupagens. Precisávamos, como professoras que fazem de suas trajetórias experiências militantes, desenvolver um perfil formativo com identidade própria. Dessa forma, além de mergulhadas naquilo que nos marca como promotoras de educação pública e de qualidade, estávamos, junto a todas as pessoas que congrega(va) $\mathrm{m}$ de uma mesma preocupação, cada uma em seu contexto, em posição de luta por condiçóes minimamente dignas de estudo e de trabalho e por reajustes salariais que não acontecem há anos.

Mais do que nunca, mantivemos firmes as atividades de ensino, pesquisa e extensáo sempre vivas, porque, com Paulo Freire, conhecemos que o tempo de espera é o tempo de quefazer. Nossa opção foi, portanto, viver essa máxima e estar de mãos dadas com aqueles com quem compartilhamos, em alguns momentos da vida, a nossa formação - seja pessoal ou profissional. E, assim, seguimos com as atividades desse projeto de extensão universitária. 


\section{Registros do cotidiano escolar de crianças, jovens e adultos}

Optamos por reunir nas açóes extensionistas que dáo origem ao livro $O$ cotidiano escolar de crianças, jovens e adultos em roda de conversas estudiosos dos contextos escolares e educativos, com atuação na educação regular e na modalidade educaçấo de jovens e adultos (EJA), que produzam pesquisas e práticas verdadeiramente inclusivas, autorais e contextuais.

Esta obra se apresenta, portanto, como uma coletânea de artigos que compartilham de um olhar incansável às complexidades da aprendizagem humana, bem como aos mais diferentes modos de ensinaraprenderensinar construídos para os alunos reais com os quais trabalhamos. Considera-se, aqui, o cotidiano das práticas pedagógicas como o espaço escolar ou institucional no qual nos formamos professores todos os dias e por meio do qual temos a oportunidade de "abrir portas" aos estudantes. Este primeiro volume congrega contribuiçóes de professores que compartilharam seus saberesfazeres em roda de conversas por meio de ediçóes das atividades de extensão universitária intituladas Educação de Jovens e Adultos em Roda de Conversas e Princípios teóricos e práticos para o cotidiano escolar de crianças, jovens e adultos em Roda de Conversas.

A fim de ampliar o diálogo com a comunidade externa à Universidade do Estado do Rio de Janeiro, objetivamos a produção acadêmica de um livro, produzido coletivamente, pelos participantes das rodas de conversas, o que se concretiza neste momento.

A proposta deste livro nasce, portanto, da necessidade que sentimos de registrar as vozes e temas abordados no projeto de extensão, por uma equipe multidisciplinar e interinstitucional. $\mathrm{O}$ que mais desejamos é que os artigos aqui apresentados se constituam como leituras que inspirem professores e licenciandos em seus processos de formação inicial e continuada. Dessa forma, disponibilizamos uma obra em que crianças, jovens e adultos, cada grupo em sua especificidade, sejam olhados em garantia de direitos. 
Na primeira parte do livro, optamos por contemplar os artigos que tratam exclusivamente da modalidade da EJA. O intuito é que possamos concentrar a atenção nas especificidades das pessoas jovens e adultas em seus processos de escolarizaçáo, tanto no que diz respeito às interações com o mundo do trabalho e às novas formas de aprender mediadas pelas relaçóes de trabalho e pelas tecnologias de informática quanto pelas referências teóricas que apoiam os estudos em EJA.

O primeiro artigo, de autoria de Enio Serra, "Currículo e cotidiano da educação de jovens e adultos", aborda a relação entre o currículo e a docência, considerando a elaboração das propostas curriculares e trazendo para o debate as necessidades e as especificidades da relação entre trabalho e educação, uma vez que a escola da EJA atende, fundamentalmente, o aluno trabalhador, além de destacar a necessidade da coletividade nos processos educativos ancorados em princípios de problematização e de libertação.

Em "Percepçóes dos sujeitos sobre o processo de escolarização na alfabetização de jovens e adultos", Jaqueline Luzia da Silva apresenta resultados da pesquisa realizada com estudantes do Programa de Educação de Jovens e Adultos (PEJA) da Secretaria Municipal de Educaçáo do Rio de Janeiro (SME/RJ) e que teve como tema a permanência e o desempenho na modalidade EJA.

O capítulo 3, de autoria de Sonia Maria Schneider, intitulado "Aprendizagem na educação de pessoas jovens, adultas e idosas, analisa a aprendizagem na e da educação de jovens e adultos", bem como noçóes, concepçôes e percepçôes que permeiam as práticas docentes.

Andrea da Paixáo Fernandes, no artigo "Paulo Freire: concepçôes de educação e apropriaçóes para a educação de jovens e adultos", traz o diálogo com Paulo Freire, convidando o leitor a refletir sobre as concepçôes para a educação somadas às contribuiçôes que o legado do autor oferece para (re)pensarmos a educação para pessoas jovens e adultas. 
Encerrando a primeira parte do livro, no capítulo "A Educação de Jovens e Adultos no contexto das transformaçóes do mundo do trabalho: uma abordagem para além das questôes mercadológicas", Carlos Soares debate a relação entre trabalho e educação no contexto da modalidade EJA, tendo por objetivo a reflexão sobre quais são os papéis da educação de jovens e adultos na sociedade atual. As reflexôes propostas por Soares possibilitam pensar na formação do trabalhador no contexto da acumulação flexível e, em contraponto, propóem a reflexão sobre a concepção de EJA na perspectiva da formação humana e integral.

Optando por práticas sempre autorais e contextuais, a segunda parte do livro contempla, em vez de métodos, princípios teóricos e práticos que possam subsidiar quefazeres sempre contextualizados e coerentes com a produção de conhecimento contemporâneo.

Abrindo essa seção, o capítulo 6, de autoria de Maria Letícia Cautela de Almeida Machado, intitulado "Fonologia aplicada à alfabetização e ao letramento: contribuições para a análise de manifestaçôes ortográficas não convencionais", analisa escritas de estudantes em processo de alfabetização de forma a subsidiar a formulação de hipóteses sobre os textos por parte de seus professores. O capítulo destaca, ainda, aspectos de mediação pedagógica para o trabalho de aproximação dessas escritas à escrita alfabética padrão.

Em "Relações entre a saúde e a educação: as ciências da visão a favor da escola", Viviam Secin discute o conceito de letramento à luz de processos vivenciados por crianças, jovens e adultos, do ponto de vista da psicomotricidade, da cognição e da visualidade. Trata-se de um diálogo interdisciplinar entre saúde e educação, com o objetivo de destacar a relação entre as dimensóes biológicas, psicossociais, ambientais, culturais, econômicas e históricas.

No oitavo capítulo, intitulado "O movimento humano em pauta: o corpo na aprendizagem de crianças, jovens e adultos", Silvio Henrique Vilela apresenta o conceito de corpo a partir da criança e da compreensão de que o ser humano é o próprio corpo. 
Corpo esse que fala, que se movimenta, que interage, que produz cultura e que aprende.

Ainda dialogando com a perspectiva do corpo, Gianne Moreira dos Santos Pereira apresenta, no nono capítulo, "Corpo e movimento no contexto da EJA", as noções de corpo, movimento e cultura em suas interfaces como parte da condição humana, destacando, sobretudo, os sentidos do componente curricular de Educaçáo Física.

Encerrando essa segunda parte e, também, a produção como um todo, em "Alfabetização: princípios e questōes didáticas", Paula Cid Lopes compartilha reflexōes sobre a própria prática alfabetizadora em turmas de crianças, jovens e adultos, buscando destacar a importância da intencionalidade pedagógica na rotina de alfabetização, bem como a relação entre os pressupostos teóricos assumidos por cada professora e as práticas de formação de leitores e escritores.

A coletânea aqui apresentada é um convite para que você, leitor, participe conosco dessas Rodas, que assumem a inclusão, a diversidade e a autoria docente como princípios de uma educação contemporânea. Compreendendo a necessidade de a educaçáo para todos ser valorizada nas políticas públicas nacionais e locais, desejamos, com este livro, fazer coro com a ideia de que "ninguém solta a mão de ninguém”. E essa ação é afirmativa e necessária quando identificamos os caminhos retrógrados assumidos para os cotidianos escolares de crianças, adolescentes, jovens, adultos e idosos.

Diante disso, você pode nos dar as mãos também, pois estar junto nesse momento é fundamental para resguardar as conquistas, as lutas e os sonhos de uma educaçáo pública e de qualidade para todos, todos mesmo.

Andrea da Paixão Fernandes e Paula Cid Lopes Rio de Janeiro, inverno de 2019 